\title{
Identification of the Emergent Leaders within a CSE Professional Development Program
}

\author{
Tracie Evans Reding, Brian Dorn, Neal Grandgenett, Harvey Siy, \\ Jon Youn, Quiming Zhu, and Carol Engelmann \\ University of Nebraska at Omaha \\ 6001 Dodge Street \\ Omaha, NE 68182 \\ \{treding, bdorn, ngrandgenett, hsiy, jyoun, qzhu, cengelmann\}@unomaha.edu
}

\begin{abstract}
The need for high quality, sustainable Computer Science Education (CSE) professional development (PD) at the grades K-12 level is essential to the success of the global CSE initiatives. This study investigates the use of Social Network Analysis (SNA) to identify emergent teacher leaders within a high quality CSE PD program. The CSE PD program was designed and implemented through collaboration between the computer science and teacher education units at a Midwestern metropolitan university in North America. A unique feature of this specific program is in the intentional development of a social network. This study discusses the importance of social networks, the development of social capital, and its impact on the sustainability of the goals of the CSE PD program. The role of emergent teacher leaders in the development of the social capital of the CSE PD cohort is investigated using SNA techniques. The cohort consisted of 16 in-service teachers in grades 6-12 representing seven districts and four distinct content areas. The instruments used involved a questionnaire and the results of a CSE PD program online course. The findings suggest a correlation between the emergent teacher leaders, the online course results, and the overall cohort social capital. Future uses of SNA within professional development programs are also discussed.
\end{abstract}

\section{CCS Concepts}

- Social and Professional Topics $\rightarrow$ K 12 Education • Humancentered Computing $\rightarrow$ Social network analysis

\section{Keywords}

Sustainable Professional Development; Social Network Analysis; Teacher Leaders; Social Capital

\section{INTRODUCTION}

Students increasingly want to learn Computer Science. In the United States, there has been an increase of $120 \%$ in the enrollment of majors in Computer Science, Computer Engineering, and Information Sciences since 2007, representing more than 100,000 total majors [14]. However, there is a noticeable discrepancy between the number of freshmen declared majors and the 500,000 open computing jobs. Overall, it has been found that $48 \%$ of all Science, Technology, Engineering, and Math (STEM) students in the U.S. leave their initial STEM field, with Computer Science/Information Sciences representing the highest attrition rates [9]. This trend is not exclusive to the U.S.; Computer Science has the highest dropout rate of all subjects in the UK [32]. The

Permission to make digital or hard copies of part or all of this work for personal or classroom use is granted without fee provided that copies are not made or distributed for profit or commercial advantage and that copies bear this notice and the full citation on the first page. Copyrights for third-party components of this work must be honored. For all other uses, contact the Owner/Author.

Copyright is held by the owner/author(s).

WiPSCE '16, October 13-15, 2016, Münster, Germany

ACM 978-1-4503-4223-0/16/10.

http://dx.doi.org/10.1145/2978249.2978254 problem might not be in the interest or motivation of the students, but may be in the student preparation. "Often these students do not have the preparation or encouragement to succeed in college-level work" [14]. This lack of exposure and student preparation of CS during K-12 years leads to uninformed educational pathway and career decisions resulting in high attrition rates.

The issue of inadequate student preparation and exposure has recently been recognized through Computer Science Education (CSE) initiatives in countries across the globe including the U.S., UK, and New Zealand that have emphasized the importance of CSE in K-12 schools. Along with these initiatives comes the realization of an urgent need for high quality, sustainable K-12 CSE professional development. This means the amount of time and money to be spent on K-12 CS PD will increase worldwide. Many educators are aware of the surge in grant money dedicated to PD during initiatives such as these; many educators are also aware of the inevitable waning of the grant money for PD once a different initiative comes into focus.

In order to make the best use of the time and money available, the sustainability and quality of CSE PD is paramount. One important aspect of sustainability in educational reform is the presence of a social network amongst the stakeholders implementing the reform. Teachers in particular recognize the importance of networks as having an impact on the sustainability of PD programs and their implementation [15]. The presence of a network/community amongst CS educators is particularly important because most High School CS teachers are "singletons", meaning they are the only CS teachers in their buildings [24]. This isolation of CS teachers highlights the need to provide PD that encourages a network amongst these teachers [38]. While the CSE PD program focused on teachers of students with an age range from 12-14 years, the importance of a community still applies not only due to the "singleton" nature of these teachers but also the relative inexperience with CSE amongst the cohort members.

Due to the CSE-specific obstacles faced, including inexperience with the content and pedagogy, lack of resources and support, and lack of national and state mandated standards, having the right people in the right places to champion this effort will boost its diffusion [8]. As numerous studies have shown, the top 10-15\% of individuals in a network emerge as leaders that act as champions of a specific cause [35]. The early identification of these "champions" can aid in the effectiveness of CSE PD programs.

This study investigates the extent to which the emergent teacher leaders can be identified from within a CSE PD cohort using SNA techniques. This CSE PD program known as the Strategic Problem-based Approach to Rouse Computer Science (SPARCS) has facilitated the development of a social network amongst the cohort members of the program. Several key topics are discussed including the importance of emergent leaders concerning CSE PD 
sustainability; possible uses of SNA with respect to CSE PD; and the implications of the findings with respect to the diffusion of the CS for All initiative.

\section{SOCIAL CAPITAL, TEACHER LEADERS, AND SPARCS 2.1 Social Capital}

The overlying concept that helps to explain the importance of the development of a network during professional development especially when it is sparse at the beginning of the program is social capital. The exact definition of social capital varies by author, context, and study. Within educational research, social capital has been defined as "the knowledge and resources for teaching practice that are accessible through a social network" [3]. There are different mechanisms identified through which social capital is generated. This study operates under the mechanism known as the network closure hypothesis that states social capital is generated through the cohesion of the members within a group [12]. The network closure hypothesis views social capital as an asset that improves the overall performance of a group due to "connectedness". This "connectedness" facilitates coordination, trust, and the spread of information [7, 12, 28].

Within social capital studies at the faculty level, most of the focus is on the effect of social capital on innovation diffusion and reform implementation. These studies demonstrate a link between increased network social capital and reform implementation [16, 26]. It has also been shown that teachers do not inherently seek out and develop social networks based on content expertise and often, teachers are unaware of their social network members' knowledge [3]. Within the network of cohort 1 of the SPARCS program, this absence of awareness of others' knowledge and expertise was evident amongst a group of three teachers that worked in the same building but were unaware of each other's CS knowledge and expertise. These findings highlight the need for any CSE PD program to facilitate and provide opportunities for professional communication and development of networks.

The extent to which networks have been fostered and developed can be analyzed through Social Network Analysis (SNA). This study functions under the understanding that "Social Network Theory and Analysis suggest that we can come to know and understand the social world by taking the relational components of phenomena into consideration" [29]. When looking at Social Network Analysis (SNA) explicitly, it is the application of specific methods to study interacting entities $[4,6,34,36]$. There are two levels of relationship structure in this study that SNA was used to investigate. SNA was initially utilized to determine the extent of development of a social network amongst the SPARCS cohort. Once the presence of relationships was established, the emphasis turned to the individual level to determine the presence of emergent leaders from within the cohort. At the individual level, it has been suggested that an individual's ability to increase the social capital of the cohort is related to their collegiality [33]. Using SNA to identify emergent teacher leaders based on their collegial skills is the focus of the paper.

\subsection{Teacher Leaders}

There are many resources dedicated to teacher leadership. Throughout these resources there are still slight differences amongst authors concerning the qualities that define a teacher leader but the overall themes are the same. These themes include collegiality, use of best practice, and supporting professional growth for all $[1,17,22]$. Teachers with these qualities tend to occupy positions of leadership whether formal or informal and this study focuses on the quantification of the collegial quality due to its relationship to the development of the whole-group social capital. Examples of positions that formal teacher leaders occupy include department chair, grade-level chair, mentor teacher, instructional specialist and coach, professional learning facilitator and any other regulated, authority appointed roles within the school and/or district. Informal teacher leader roles are much more difficult to categorize because they are not recognized formally and emerge as teachers interact with their peers. Informal teacher leaders are faculty members that are not appointed to positions of authority or given special titles but hold an influential position within the social network of the organization $[20,27,31]$.

There are many reasons that teacher leaders are crucial to the success of reform implementation and sustainable PD. For example, teachers' attitudes toward the proposed reform play a major role in the fidelity of reform implementation. During initial reform implementation, teachers tend to seek advice and knowledge from peers within their established networks that in turn influence network member attitudes. These peers do not necessarily occupy a formal leadership position. There is also an evident difference between the intended, formal knowledge pathways and the actual knowledge pathway that occurs in the social networks entrenched within the organization but outside of the formal appointed networks $[13,21]$. This realization makes it necessary to uncover the informal pathway in order to leverage it for the purposes of information diffusion and to also promote relationships at all levels within the PD program in order to influence the social networks of the individuals. The identification of the informal leaders that are adept at building these collegial relationships is necessary in order to leverage their skills to build social capital of the group.

Formal teacher leaders such as instructional coaches have been shown to play an important role in the fidelity of reform implementation [2, 10, 11]. While numerous studies have been conducted on the necessity of formal teacher leaders and reform implementation, not much research has been conducted concerning informal teacher leaders most likely because they are difficult to identify. This study specifically uses SNA to identify the emergent teacher leaders at the collegial, yet informal relationship level that demonstrates collegiality outside of the formal subgroup memberships.

\subsection{SPARCS}

In order to provide some context of the activities the cohort members engaged in while developing these relationships, this section briefly discusses the overall goals and activities of the SPARCS program. The SPARCS program has several anticipated outcomes as a result of the activities and outputs of the project including: increased teacher CS knowledge; enhanced school capacity for CS instruction; increased student CS knowledge; and increased student awareness of CS careers. The activities related to the data collected for this study occurred during the summer of 2015. There were 16 teachers accepted that participated in the summer professional development, and these 16 teachers make up the population of this study. The project began with a teacher institute that was a weeklong workshop with a focus on the basics of CS and inquiry based learning strategies. At the end of this week, teachers were divided into four subgroups based on their intended curricular focus for the CS lesson. Two groups had a curricular focus of computer applications, one group had a curricular focus of science, and one group had a curricular focus of math/high ability learners. The next activity was an individual 
online course with an emphasis on computational thinking and programming. The second teacher institute was also a weeklong workshop that focused on the inquiry based lesson development where teachers worked almost exclusively in their curricular focus groups. These groups make up the formal, mandated relationships that are not the focus of this study. While these relationships are important, it is also expected that relationships were formed at this level. At the end of the summer portion of the project, there was a weeklong student academy that functioned as a pilot run for the lessons that were developed the prior week.

As part of the SPARCS program there were also meetings that occurred throughout the academic year. These monthly meetings were held with various themes at each meeting. For example, one meeting reviewed some of the basic CS principles that were addressed through the summer while a separate meeting asked teachers to reflect upon their lesson's strengths, weaknesses, and future improvements. These meetings are beyond the scope of focus for this article.

As mentioned earlier, it is expected that relationships would be formed within the curricular focus groups that worked together to develop their lessons. The relationships that were formed outside of these formal groups are the primary interest of this study because it highlights those teachers that have the collegial skills to form relationships that are not mandated, professional in nature, yet more informal. This study asks the question:

How can the informal, emergent teacher leaders within the SPARCS cohort be identified?

\section{METHODOLOGY}

The goal of this study was to identify emergent teacher leaders at the collegial, yet informal level using cohort member responses on a questionnaire. Results of an online course were also used to initially determine content knowledge of the emergent leaders.

\subsection{Subjects}

The participants of the SPARCS project consisted of 16 in-service teachers from the Omaha metro area. Teachers were selected through a process that reviewed their applications, resumes, and principal reference letters. Fifteen of the sixteen teachers were from schools serving students with age ranges from 12-14, and one teacher was from a high school (students with ages 14-18). Five teachers had a content area focus of science, three teachers were high ability learner teachers, and eight teachers had a content area focus of computer applications.

\subsection{Instruments}

Two separate instruments were used in this study, a social network analysis survey, and the results of the online course. The social network analysis consisted of a questionnaire modeled on Morrison et. al.'s previous work examining community development among high school CS teachers [23]. The questionnaire was presented in roster format where each individual was listed and four different levels of relationship could be selected. Participants took the presurvey the first day of the first weeklong teacher institute and the post-survey was completed on the last day of the second weeklong institute, six weeks later. The participants self-reported the perceived level of relationship between themselves and each other participant in the cohort. The levels were numbered 1-4 and were categorized by the following statements:

1. I have never met this person;

2. I have met this person but have never shared advice or materials;
3. We have shared materials and ideas but have never formally worked together on a project;

4. We have formally worked on a project together.

Each cohort member could only select one level of relationship for each other cohort member. For the purposes of identifying the emergent leaders, the level 3 relationships were examined due to the collegial, unprescribed nature of these relationships.

The second data source was the online course that was developed specifically for the SPARCS program. Performance on the selfpaced online course was based on the number of completed assignments considered proficient. This measurement was necessary in order to determine content knowledge and, indirectly, responsibility, professionalism, and a willingness to learn which are other important aspects of teacher leaders.

\subsection{Method}

As discussed earlier, SNA is a powerful tool for examining relationships and was the method by which the results of the questionnaire were analyzed. After collecting the pre and postsurveys, the first step was to determine which SNA specific software to use for data analysis. The chosen software was a Microsoft Excel add-in known as NodeXL pro. The purpose of this add-in is to enable users the ability to perform network analyses with novice level programming knowledge. More specifically, it was designed to analyze social media networks such as Twitter but in this case, it was used to analyze "face-to-face" social networks.

The first step was to enter the self-reported ties (relationships) between two actors according to the respondent's (actor 1) survey along with the level of relationship as reported by that respondent. This was completed for all 16 cohort members for both the pre- and post-surveys. The next step was to run the metrics available through NodeXL pro and compare the pre- and post-survey results.

After the overall metrics had been calculated concerning the development of a network, the focus moved to identifying the emerging leaders. The goal of identifying emergent leaders based on their collegial, informal relationships narrowed the focus to the level 3 relationships "We have shared materials and advice but have never formally worked together on a project". This ties back to the research findings that advice and knowledge diffusion occurs within the informal network structure rather than the formal network structure. Results are discussed in Section 4.1.

With the purpose of identifying informal teacher leaders based on their ability to increase collegial ties within the cohort, the two metrics used at the individual actor level were degree and betweenness centrality. The degree metric of an actor is the number of unique ties that are connected to it; the greater the number of unique ties, then the greater the degree metric. This is an important metric in the formation of collegial ties because it increases the possible awareness of resources within the actor's network. The betweenness centrality metric of an actor is a measurement of the magnitude to which the actor is a link for two otherwise unconnected actors, the greater the extent to which an actor is a link, the greater the betweenness centrality. This demonstrates the linking actor's ability to share the ideas among otherwise unconnected actors which is a necessary component of promoting collegiality and social capital [5].

Intending to combine these two metrics, a necessary scoring conversion was used because the individual intervals are not the same between the degree metric and the betweenness centrality metric. The metrics for both degree and betweenness centrality were then separately converted to a scoring scale for the cohort members. The member(s) with the highest degree metric were 
given a degree score of 1 . The member(s) with the second highest degree metric were given a degree score of two, and so on. This scoring system was also completed for the betweenness centrality measures. The individual scores for each cohort member were then added together to determine overall collegial scores of each cohort member. The lower the combined number, the better the collegial score (closer to 1). It must be noted that due to the small population size, there were ties in the collegiality scores. This was not interpreted as a ranking order but rather a score so the ties were left the same, for example, if two actors received a collegial score of 8 , they both received an 8. It is possible that the next individual would have a combined score of 9 , and would therefore receive a 9 as their collegiality score.

Once each member had a collegial score, they were removed from the network and the whole-network metrics were calculated again, focusing on the density metric. This was done to determine the effect each individual had on the whole network density, a measure of the social capital of the group [5]. The density metric that resulted from the removal of an individual is known as the wholenetwork member excluded density. The amount of difference from each member's whole network excluded density from the original whole network density was calculated to determine the effect of each cohort member on the overall density of the cohort. Results are outlined in Section 4.2.

The next data set analyzed was the results of the online course. Performance on the online course was used to determine teachers that demonstrated they learned the intended content knowledge, in indirectly demonstrated responsibility, professionalism, and a willingness to learn, which are important features of an emergent leader. Cohort members' performance on the online course was based on completion of the six assignments. A Spearman

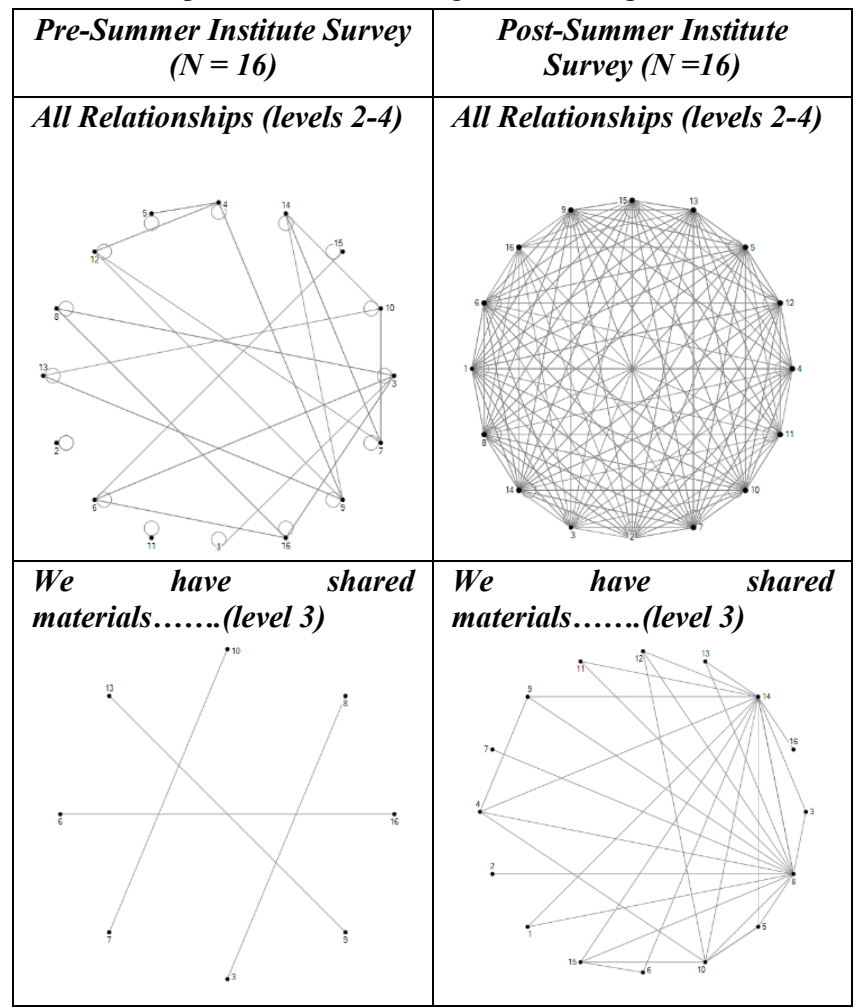

Figure 1. NodeXL visual representation of the actors (nodes) and the reported relationships (edges) for the pre and post summer surveys at levels 2-4 combined and level 3 alone.
Table 1. Density and total edges for all relationships and level 3 relationships only for pre and post summer surveys.

\begin{tabular}{|l|c|c||c|c|}
\hline $\begin{array}{l}\text { Cohort } \\
(\mathbf{N}=16)\end{array}$ & \multicolumn{2}{|l||}{$\begin{array}{l}\text { All relationships } \\
\text { (levels 2-4) }\end{array}$} & \begin{tabular}{l} 
We have $\begin{array}{c}\text { shared } \\
\text { materials... } \\
\text { only) }\end{array}$ \\
\cline { 2 - 5 }
\end{tabular} & Prevel 3 \\
\hline Density & 0.15 & 0.975 & 0.07 & 0.13 \\
\hline Total Edges & 46 & 212 & 4 & 36 \\
\hline
\end{tabular}

correlation was conducted to determine the extent of correlation between the overall collegial scores, the online course scores, and the whole-network member excluded density metrics. Results are outlined in section 4.3.

\section{RESULTS and ANALYSIS}

\subsection{Relationship Metrics}

The formation of relationships was expected and confirmed for all relationships levels. As shown in Figure 1 and Table 1, the density for Cohort 1 increased for all relationships and indicates an increase in the interconnectedness of the cohort members. This increase went from 0.15 to 0.975 , with a density metric of 1 representing complete interconnectedness. The total edges reported increased for all degrees of relationships from 46 to 212 and the results show an increase in the total number of relationships reported.

It should be noted that for the pre survey results, three teacher self reported not knowing anybody else and were represented as selfloops. In order to minimize the effect of the self-loops, all teachers were given self-loops for the pre and post surveys and the metrics reflect this.

More importantly, the density and total edges also increased for the level three relationships based on the statement "We have shared materials and ideas but never formally worked together on a project". The density increased from 0.07 to 0.13 and the total edges increased from 4 to 36 . This statement reflects the informal, yet collegial relationships within the cohort, which was the level of relationship focused upon for the identification of informal, emergent leaders.

\subsection{Identification of Emerging Leaders}

After it had been shown that relationships had been formed, the focus shifted to the identification of the informal, emergent teacher leaders. Figure 2 is a NodeXL graph plotting betweenness centrality score vs. degree score of each cohort member. The nodes represent the actors with their numeric identifiers. The edges represent ties between the actors. The closer to $(1,1)$ the better the collegiality score. The farther from $(1,1)$, the worse the collegiality score. Note there are several nodes with multiple identifiers indicating the ties at those collegial scores.

Figure 2 represents that actor 8 had the best collegial score of 2 $(1,1)$. Actor 14 had the second best collegial score of $3(1,2)$. Actors 10 and 15 had a collegial score of $5(2,3)$ and $(3,2)$ respectively. Actors 7 and 2 both had the worst collegiality scores of $12(6,6)$. Figure 3 illustrates the difference from the wholenetwork density score for each cohort member when they were removed. " 0 " is the baseline representing the whole network density metric when all members are present. Negative scores indicate when those members were removed from the network, the 


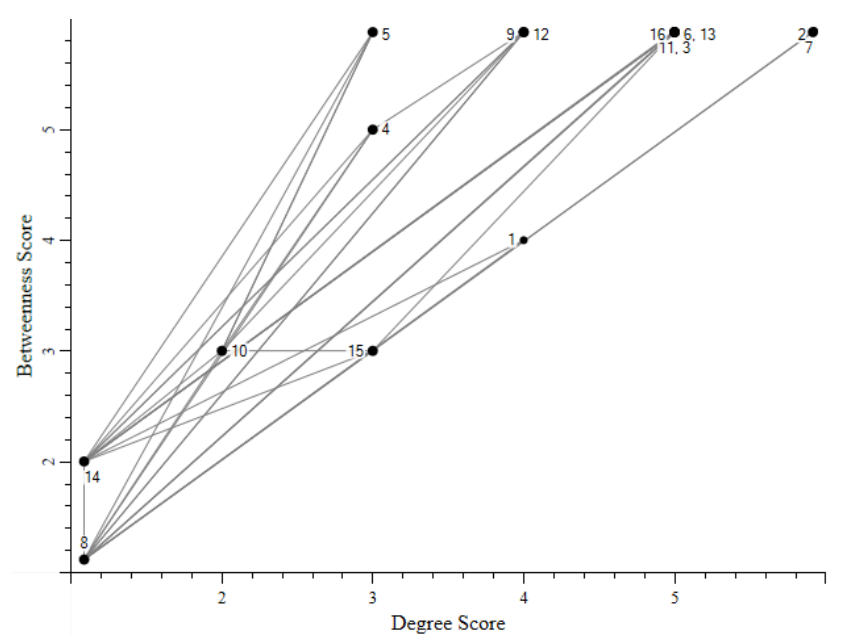

Figure 2. Betweenness Centrality Score vs. Degree Score of the Cohort Members.

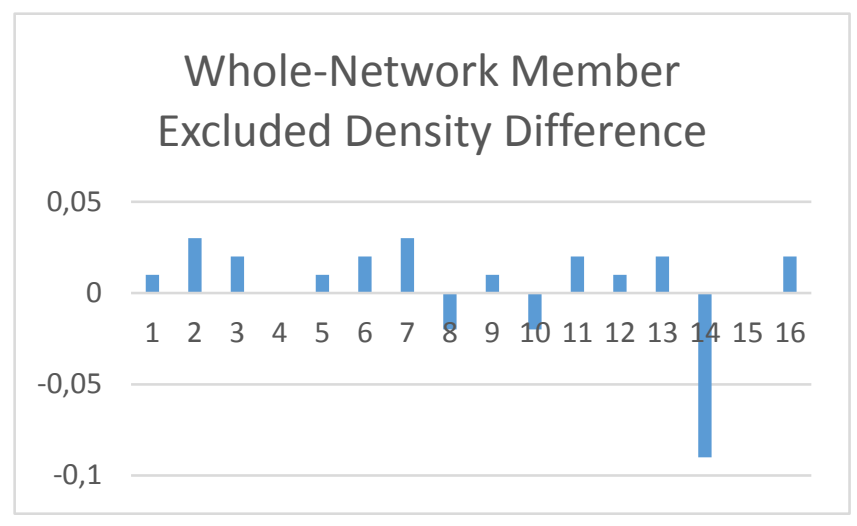

Figure 3. Whole-Network Member Excluded Density Difference.

overall density of the network decreases. For example, when cohort member 14 was removed from the network, the wholenetwork density metric decreased from 0.27 to 0.18 , a difference of -0.09. Positive scores indicate when those members were removed from the network, the overall density of the network increases. For example, when cohort member 2 was removed from the network, the whole-network density metric increased from 0.27 to 0.30 , a difference of 0.03. "Blank" scores show a difference of zero indicating those members had no effect on the density when removed. Considering this along with the results shown in Figure 2 , it seems reasonable to identify actor 14 as an obvious emergent leader, with actor 8 as a plausible emergent leader as well. These results fall in line with the expected percentage of $10-15 \%$ of the individuals identified as leaders within any network [35].

It should also be noted that after this research was conducted, it was discovered that there is a program called "Key Player" that identifies actors to either target with the intent of using them to diffuse information within the network or target with the intent of disrupting the connectedness of the network. A Spearman correlation showed a significant correlation of 0.889 with a p-value $<0.01$ between the collegial scores determined in this study and the identification of Key Players using the Key Player software. This implies a connection between the determination of the emerging leaders based on their impact on social capital and nodes to remove using distance weighted fragmentation correlation in Key Player. Key Player also has a separate algorithm for determining nodes using distance-weighted reach criterion. The top four emerging leaders match the top four nodes to utilize according to Key Player. This provides validty for the method used in this study.

\subsection{Correlations}

Table 2 shows the Spearman correlations between the collegial scores, the online course scores, and the whole-network density excluded scores. $\mathrm{N}=16$ for all variables. Collegial score was determined by combining the resulting scores of the degree and betweenness centrality metrics. The online course score was determined by the completion of the six assignments on the SPARCS specific online course. The whole-network member excluded density metric was determined by removing each individual from the network and calculating the density metric without that member present. There is a significant positive correlation between the collegiality score and the whole-network member excluded density metric of 0.96 and implies a connection between an actor's collegial skills and the social capital of the group. There is also a significant negative correlation between the collegiality score and the online course score of -0.64 that implies a connection between an actor's strong collegial skills and better performance on the online course. There is also a significant negative correlation between the online course score and the wholenetwork density excluded metric of -0.65 which implies a connection between an actor's online course performance and that actor's contribution to the social capital of the cohort. It is necessary to note that the small population size of 16 does reduce the statistical power of the Spearman correlation but because the $\mathrm{p}$ level is $<0.01$ and the resulting correlations are demonstrated, the correlations themselves can be considered significant in spite of the small population size.

Table 2. Spearman correlations of collegial score, online course score, and whole-network member excluded density (MED) metric.

\begin{tabular}{|l|l|l|l|}
\hline $\begin{array}{l}\text { Cohort 1 } \\
(\mathbf{N}=16)\end{array}$ & $\begin{array}{l}\text { Collegial } \\
\text { Score }\end{array}$ & $\begin{array}{l}\text { Online } \\
\text { Course } \\
\text { Score }\end{array}$ & MED Metric \\
\hline $\begin{array}{l}\text { Collegial } \\
\text { Score }\end{array}$ & & $-0.64^{*}$ & $0.96^{*}$ \\
\hline $\begin{array}{l}\text { Online } \\
\text { Course } \\
\text { Score }\end{array}$ & $-0.64^{*}$ & & $-0.65^{*}$ \\
\hline MED Metric & $0.96^{*}$ & $-0.65^{*}$ & \\
\hline
\end{tabular}

Notes: ${ }^{*} \mathrm{p}<0.01$

\section{CONCLUSION}

The purpose of this study was to determine how SNA could be used to identify informal, emergent teacher leaders from within the SPARCS cohort. These emergent leaders are important to identify because of their crucial role in the development of the social capital of the group and therefore the sustainability of the CSE PD. This study demonstrated that SNA could be used to identify emergent leaders successfully by first looking at the SNA metrics of degree and betweenness as a scoring calculation for each individual's collegial skills. Then, by removing each of them from the network, 
their individual impact on the group's social capital was demonstrated. A correlation amongst the collegial skills, impact on the group's social capital, and online course results were also performed. Using this method, two emergent teacher leaders were identified, and two other possible emergent teacher leaders were also identified. This method also strongly correlates with the Key Player method, which provides validity to the method used in this study.

\subsection{Limitations}

There are limitations that must be noted. The cohort size of 16 is relatively small so parametric correlations such as Pearson could not be used. The non-parametric Spearman correlation was used instead and produces results with notable significance. Also, the survey used as the basis of determining collegiality and social capital is of the self-reporting nature and brings with it all of the typical limitations associated with this type of survey namely social desirability bias and reference bias. Social desirability bias occurs when a respondent selects "higher" ratings in order to be perceived as more attractive to peers. Reference bias is the influence of different standards of comparison among respondents [37]. These limitations affect all questionnaires and further research is needed in order to minimize their impact on the data collected. It should also be highlighted that when comparing the results of this study to larger networks of teachers, the teachers in this study voluntarily applied to this CSE PD. This presents considerable bias on the participants' view of CSE in general which may have affected their ability to develop a network in such a CSE focused program.

\subsection{Discussion}

While this research consisted of a relatively small network of teachers, SNA itself is often used as an inductive approach to understand larger networks. This discussion section considers the findings of this study from a relatively small network and discusses the implications for large-scale networks of teachers while acknowledging the intrinsic differences. Large-scale teacher networks are already in place within schools and districts and the inherent communication processes are vital parts of the success of any reform such as the CSE initiatives. Several of these initiatives across the globe, such as Computer Science for All in the U.S., and Computing at School in the UK, are fundamentally systemic changes with far-reaching social impacts $[8,25]$. These types of changes are not only reforms but also considered innovations and it is reasonable to approach them through the lens of Innovation Diffusion Theory. The Diffusion of Innovations Theory is a framework intended to explain how new ideas are communicated throughout a social network over time and how those ideas are adopted [30]. Generally speaking within education, the Diffusion of Innovations Theory is applied to technology specific initiatives. The author does not mean to imply that CS is simply a "technological adoption". CS involves much more than just using technology in the classroom, it is a curricular and pedagogical innovation but there are parallels when comparing the adoption of technology use in the classroom with CS specific curriculum and lessons in the classroom. The biggest similarity is the "newness" surrounding these innovations which cause their diffusion and adoption to be complex.

Within the Diffusion of Innovations Theory, there are individuals that increase the rate and scale of the adoption of "new initiatives" such as the Computer Science for All initiative. This study focused on the impacts of individuals on the social capital of the group that has been shown by other studies to affect the adoption of reform. The connection between group social capital and innovation diffusion is highlighted by the fact that social capital leverages existing expertise and network qualities and can be applied not only to innovation diffusion but more importantly, innovation implementation [16]. Often times, the individuals that increase the rate of adoption of innovations are different individuals than those that increase the scale of adoption. Traditionally, individuals that increase the rate of adoption have high betweenness and a low degree metric, and are known as "gatekeepers". On the other hand, those that increase the scale of adoption have low betweenness centrality with a high degree metric and are known as hubs $[18,30]$. The findings in this study suggest that there are individuals that act as both "hubs" and "gatekeepers" simultaneously which implies these individuals can increase both the rate and scale of adoption of the CS for All initiative, along with other CSE innovative initiatives, and alternatively, delay them if they are not engaged well.

Another study has suggested there are individuals that act as bridges (gatekeepers) and know a large number of people (hubs) and that these individuals increase the spread of information [19]. The SPARCS study suggests that these individuals with high collegiality, which match the combined characteristics of hubs and gatekeepers, also share another important characteristic, the willingness to learn. While this characteristic was indirectly implied through the online course scores, it is important to note that four out of the sixteen teachers entered the PD program with more than novice CS knowledge. Three out of four of these "CS experienced" teachers did not complete the online course. When the one CS experienced teacher that did complete the online course, teacher 14, was removed, the greatest disruption in social capital for the cohort was demonstrated. When the other three CS experienced teachers were removed from the network, the social capital of the network actually increased. There are many variables to take into consideration when attempting to explain this. A possible explanation is that even though teacher 14 had experience with CS, this teacher also had a willingness to learn, not only about the content as demonstrated by the online course results, but also a willingness to learn about the other members of the network as professionals, as demonstrated by the collegiality score.

It is important to recognize that as the shift for CSE is changing from a specialty area within education to a subject on par with basic sciences that all students receive, much more in-service teacher PD will be needed to make this happen [8]. When these teachers look for advice and guidance regarding CSE, they will turn to their collegial peers. Individuals who are willing to learn content specific material and engage with their peers as professionals should be sought after not only to participate in these early CSE PD programs, but also to become champions of the CSE initiatives. Adoption and sustainability of this PD depends largely on the social network developed amongst the members trying to implement the changes. While content knowledge is often highlighted as an important individual attribute when seeking out people to act as champions of content-specific innovations, such as CSE PD, the willingness to learn and develop collegiality within the network is an important quality to consider as well.

Within research consisting of educational reform and innovation, SNA and social capital considerations within CSE are emerging. In the near future, SNA will be one method used to examine the success of the development of a community of practice within the CSE PD program and to identify the emergent leaders among the cohort. SNA and CSE can also be examined through the Diffusion of Innovations Theory lens with the possibility of using SNA to not only identify emerging leaders to act as champions, but also to examine the impact of the networks on the diffusion of CSE initiatives. SNA can also be used as an evaluative tool on other 
grants and programs that are intending to generate sustainable networks and communities of practice. The possibilities of SNA appear to be far-reaching and in the near future may be used during the planning process of CSE PD programs in which SNA will be used to inform personnel decisions in order to ensure the development of social capital and therefore sustainability of the program. It is also possible due to its social media ties, to use SNA to perhaps recruit specific, emerging leaders from online education online communities, in order to train them to deliver PD to other teachers therefore broadening the impact of the CSE PD.

\section{ACKNOWLEDGEMENTS}

This work is funded in part by the National Science Foundation under grant DRL-1433788. Any opinions, findings, and conclusions, or recommendations expressed in this material are those of the authors and do not necessarily reflect the views of the NSF.

\section{REFERENCES}

[1] Andrew, M. D. Teacher Leadership: A Model for Change. Bulletin 37, Association of Teacher Educators, Washington, D.C., 1974.

[2] Atteberry, A. and Bryk, A. S. Centrality, connection, and commitment: The role of social networks in school-based literacy. In Daly, A. J. ed. Social network theory and educational change, pages 51-76, Harvard Education Press, 2015.

[3] Baker-Doyle, K. J. and Yoon, S. A. In Search of PractitionerBased Social Capital: A Social Network Analysis Tool for Understanding and Facilitating Teacher Collaboration in a US-Based STEM Professional Development Program. Professional Development in Education, 37(1):75-93, 2011.

[4] Balkundi, P. and Kilduff, M. The ties that lead: A social network approach to leadership. The Leadership Quarterly, 17(4): 419-439, 2006.

[5] Borgatti, S. P., Jones, C. and Everett, M. G. Network measures of social capital. Connections, 21(2):27-36, 1998.

[6] Borgatti, S. P., Mehra, A., Brass, D. J. and Labianca, G. Network analysis in the social sciences. Science, 323(5916): 892-895, 2009.

[7] Bourdieu, P. and Wacquant, L. J. An invitation to reflexive sociology. University of Chicago press, Chicago, IL, 1992.

[8] Brown, N. C. C., Kölling, M., Crick, T., Peyton Jones, S., Humphreys, S. and Sentance, S. Bringing computer science back into schools: lessons from the UK. In Proceeding of the 44th ACM technical symposium on Computer science education, pages 269-274, 2013.

[9] Chen, X. and Ho, P. Web Tables: STEM in postsecondary education: Entrance, attrition, and course taking among 2003-2004 beginning postsecondary students. National Center for Education Statistics, Washington, D.C., 2012.

[10] Coburn, C. E., Choi, L. and Mata, W. "I would go to her because her mind is math": Network formation in the context of a district-based mathematics reform. In Daly, A. J. ed. Social network theory and educational change, pages 33-50, Harvard Education Press, 2015.
[11] Cole, R. P. and Weinbaum, E. H. Changes in attitude: Peer influence in high school reform. In Daly, A. J. ed. Social network theory and educational change, pages 77-96, Harvard Education Press, 2015.

[12] Coleman, J. S. Social capital in the creation of human capital. American journal of sociology, 94:S95-S120, 1988.

[13] Cross, R., and Parker, A. The hidden power of social networks. Harvard Business School Press, Boston, MA, 2004.

[14] desJardins, M. Explainer: what it will take to make computer science education available in all schools. The Conversation, 2015. Last Accessed Aug 2016: http://theconversation.com/explainer-what-it-will-take-to$\underline{\text { make-computer-science-education-available-in-all-schools- }}$ $\underline{47746}$

[15] Fairman, J. C. and Mackenzie, S. V. How teacher leaders influence others and understand their leadership. International Journal of Leadership in Education, 18(1), 61-87, 2015.

[16] Frank, K. A., Zhao, Y. and Borman, K. Social capital and the diffusion of innovations within organizations: The case of computer technology in schools. Sociology of Education, 77(2):148-171, 2004

[17] Frost, D. and Durrant, J. Teachers as Leaders: Exploring the impact of teacher-led development work. School Leadership \& Management, 22(2):143-162, 2002.

[18] Goldenberg, J., Han, S., Lehmann, D. R. and Hong, J. W. The role of hubs in the adoption process. Journal of Marketing, 73(2), 1-13, 2009.

[19] Guimarães, A., Vieira, A. B., Silva, A. P. C. and Ziviani, A. Fast centrality-driven diffusion in dynamic networks. In Proceedings of the 22nd International Conference on World Wide Web. Pages 821-828, 2013.

[20] Killion, J. and Harrison, C. Taking the lead: New roles for teacher leaders and school-based staff developers. National Staff Development Council, Oxford, OH, 2006.

[21] Krackhardt, D. and Hanson, J. R. Informal networks. Harvard Business Review, 71(4):104-111, 1993.

[22] Merideth, E. Chapter 1: Teachers as Leaders. In Leadership Strategies for Teachers, pages 1-19, Corwin, Thousand Oaks, CA, 2006.

[23] Morrison, B. B., Ni, L. and Guzdial, M. Adapting the disciplinary commons model for high school teachers: improving recruitment, creating community. In ICER'12: Proceedings of the ninth annual conference on International Computing Education Research, pages 47-54, 2012.

[24] Ni, L., Guzdial, M., Tew, A. E., Morrison, B. and Galanos, R. Building a community to support HS CS teachers: the disciplinary commons for computing educators. In SIGCSE'11: Proceedings of the 42nd ACM Technical Symposium on Computer Science Education, pages 553-558, 2011.

[25] Office of the Press Secretary. FACT SHEET: President Obama Announces Computer Science for All Initiative. 2016, Last Accessed Aug. 2016: https://www.whitehouse.gov/thepress-office/2016/01/30/fact-sheet-president-obamaannounces-computer-science-all-initiative- 0 
[26] Penuel, W., Riel, M., Krause, A. and Frank, K. Analyzing teachers' professional interactions in a school as social capital: A social network theory approach. The Teachers College Record, 111(1):124-163, 2009.

[27] Penuel, W. R., Frank, K. A. and Krause, A. Between Teachers and Leaders: Using Social Network Analysis to Examine the Effects of Distributed Leadership. In Daly, A. J. ed. Social Network Theory and Educational Change, pages 159-178, Harvard Education Press, Cambridge, MA, 2015.

[28] Putnam, R. D. Bowling alone: The collapse and revival of American community. Simon and Schuster, New York, NY, 2001.

[29] Quatman, C. and Chelladurai, P. Social network theory and analysis: A complementary lens for inquiry. Journal of Sport Management, 22(3):338-360, 2008.

[30] Rogers, R.M. Diffusion of Innovations. Free Press, New York, NY, 1995.

[31] Spillane, J. P., Healey, K. and Kim, C. M. Leading and Managing Instruction: Formal and Informal Aspects of Elementary School Organization. In Daly, A. J. ed. Social Network Analysis and Educational Change, pages 129-158, Harvard Education Press, Cambridge, MA, 2015.

[32] The Telegraph. University Degree Subjects with the Highest Dropout Rates. Last Accessed Aug 2016: http://www.telegraph.co.uk/education/educationpicturegalleri es/11002595/University-degree-subjects-with-the-highestdropout-rates.html

[33] Uekawa, K., Aladjem, K. and Zhang, Y. The role of social capital in comprehensive school reform. Paper presented at the annual meeting of the American Educational Research Association, Montreal, Canada, 2005.

[34] Valente, T. W. Social networks and health: Models, methods, and applications. Oxford University Press, Oxford, UK. 2010.

[35] Valente, T. W. Network interventions. Science, 337(6090):4953, 2012.

[36] Wasserman, S. and Faust, K. Social network analysis: Methods and applications. Cambridge University Press, Cambridge, UK, 1994.

[37] West, M. R. The Limitations of Self-Report Measures of Non-cognitive Skills. The Brown Center Chalkboard Series, 2014. Last Accessed Aug 2016: https://www.brookings.edu/research/the-limitations-of-selfreport-measures-of-non-cognitive-skills/

[38] Yadav, A., Gretter, S. and Hambrusch, S. Challenges of a Computer Science Classroom: Initial Perspectives from Teachers. In Proceedings of the Workshop in Primary and Secondary Computing Education, pages 136-137, 2015. 